CONTROVERSY

\title{
Predictive Genetic Testing in Minors for Adult-Onset Genetic Diseases
}

\author{
Pascal Borry, Tom Goffin, Herman Nys and Kris Dierickx \\ Centre for Biomedical Ethics and Law, Katholieke Universiteit Leuven, Leuven, Belgium
}

\begin{abstract}
This article analyses the ethical discussion of predictive genetic testing in minors for genetic conditions for which there is no phenotypic evidence for disease at the considered time of testing and for which there is currently no treatment available to prevent or forestall the development of the condition. After a presentation of the position of various professional guidelines, we discuss the position and arguments that have been advanced in a recent article that defends a position that is opposed to the professional recommendations. In the article, we discuss the position of voluntary choices and autonomous and informed decision-making in a context of open communication. Thereafter, we analyze the nonmedical benefits and harm related to this type of testing. Finally, we critically analyze 4 arguments: the potential provision of good news if a test is performed, the unbearability of knowing, identity and adjustment, and parental anxiety and uncertainty. Mt Sinai J Med 75:287-296, 2008. (C) 2008 Mount Sinai School of Medicine
\end{abstract}

Key Words: adult-onset genetic diseases, genetic diseases, genetic testing, predictive testing.

Presymptomatic and predictive genetic testing makes it possible to trace a genetic defect before the manifestation of symptoms. On the one hand, this offers

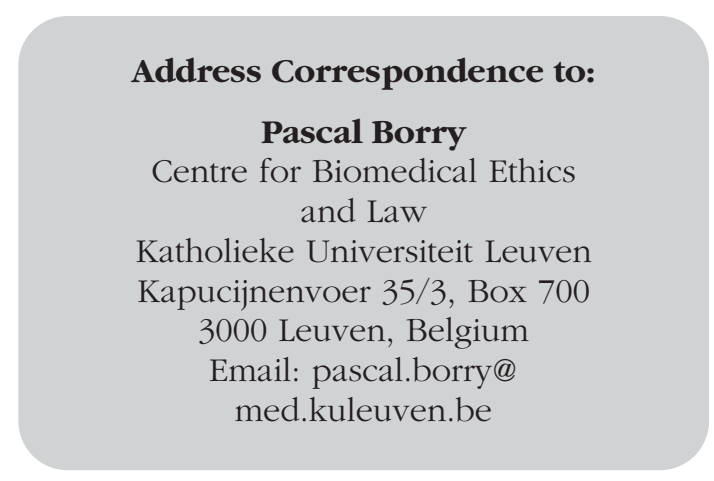

the advantage that individuals who carry a genetic risk can find out more concerning their future health risks, whereas they remained uncertain in the past. On the other hand, this has led to ethical discussions about whether or not a certain test should be carried out and also about how and in what manner this test should be carried out. Predictive genetic tests may have far-reaching consequences for test applicants, their family members, and society. ${ }^{1}$ As a result, ethical reflection ${ }^{2,3}$ has always been concerned with the careful transfer of information about genetic tests and test results, the confidentiality of genetic information, the voluntariness of requesting a genetic test, the responsibility toward blood relatives, and the (potential) psychosocial impact of a test on the applicant. ${ }^{4}$ An even more cautious approach has been envisaged when such testing is considered in children and adolescents. This originates from the fear that testing in childhood or adolescence could create devastating social, emotional, psychosocial, and educational consequences in the child or adolescent.

In this article, we analyze the ethical discussion of predictive genetic testing for genetic conditions for which there is no phenotypic evidence for disease at the time of testing and for which there is currently no treatment available to prevent or forestall the development of the condition. In particular, we discuss the policies for predictive testing of minors for adult-onset genetic conditions (eg, Huntington's disease and polycystic kidney disease). To avoid confusion in terminology, by minors we mean all persons who have not reached the age of majority (which is in most countries 18 years).

In the first part of the article, we present the positions of various genetic and medical guidelines with respect to predictive genetic testing of minors for adult-onset diseases. In the second part of the article, we discuss how the guidelines have emphasized that requests for predictive genetic tests for adult-onset diseases should be voluntary and should come from 
a competent applicant, without any form of pressure. In the third part of this article, we analyze how the perspective of nonmedical benefits and harm is affecting the discussion on this type of testing. In the article, we refer to and comment on the positions and arguments that have been used in an article of Rhodes $^{5}$ that was recently published in this journal. In that article, the author defends a position that is "diametrically opposed to the policies and guidelines of the genetics and pediatric communities." Rhodes concluded that

Pediatricians and geneticists should encourage parents to pursue genetic testing of children at a young age. ... Pediatricians and geneticists should encourage reluctant parents to have their children tested-and then accept the parents' decision.

In light of this article by Rhodes, a more extensive and elaborate debate on the issue of predictive genetic testing in minors for adult-onset genetic diseases seemed appropriate to us.

\section{POLICIES, GUIDELINES, AND RECOMMENDATIONS}

In the last decade, various genetic and medical associations have published guidelines ${ }^{6-13}$ regarding predictive genetic testing in minors. All guidelines clearly put forward that medical benefit is the main justification for testing minors for adultonset diseases. They stress in a similar way that predictive genetic testing should be performed only for persons of legal age, except for disorders for which preventive or therapeutic actions could be initiated. They clearly advance in similar words that, when they are talking specifically about predictive and presymptomatic tests for late-onset disorders, such testing is recommended only when "established, effective, and important medical treatment"14 can be offered or when testing "provides scope for treatment which to any essential degree prevents, defers or alleviates the outbreak of disease or the consequences of the outbreak of disease."15 The rationale is that medical benefit to the child should be the primary justification for genetic testing in children and adolescents. The availability of preventive or other therapeutic measures leads in some cases even to the requirement to perform a genetic test. ${ }^{13}$ Also, some disease-specific guidelines have been elaborated and put forward a similar position. In the case of Huntington's disease, for example, the International Huntington Association and the World Federation of Neurology already published in 1990 a policy statement concerning the provision of the test to minors. In the revised version of 1994, the text still kept the provision that the test should be available only to "those having reached the age of majority."

Although in most countries a person's 18th birthday draws the line between childhood and adulthood, most clinical-ethical guidelines do not use this demarcation as a strict rule for accepting or refusing genetic testing for adult-onset diseases. In the case of late-onset diseases, it is emphasized that age "should be given flexible consideration"16 and that genetic tests should be deferred as much as possible to the moment adolescents are "competent to make a free informed decision." 17 The rationale behind this option is that predictive testing for adult-onset diseases "should be delayed until the person is old enough to make an informed choice."18 "The degree of maturity and state of development"14 and "conditions of competence, voluntariness, and adequate understanding of information" 6 are considered crucial criteria in the assessment of adolescents' requests for genetic testing. Clinical-ethical guidelines should of course always be assessed in the particular legal context in which they have been elaborated. Legal provisions on the age of medical majority ${ }^{19}$ contextualize the professional recommendations on the age at which minors can consent to predictive genetic testing; for example, it is clear that Danish law on patients' rights ${ }^{20}$ supports the professional recommendation that competent patients between 15 and 18 years may personally give informed consent to genetic testing after the person holding parental authority has been informed and allowed to participate in the decision-making. These clinical-ethical guidelines stress that children should receive education and counseling appropriate to their age and maturity. Postponing testing is not considered a reason to avoid discussing the issues of genetic risk and/or genetic testing with younger children. ${ }^{10}$

\section{PERSONAL REQUEST}

Predictive genetic tests provide information about the medical future of a healthy person. In this sense, there is a substantial difference between a predictive genetic test and a traditional medical diagnosis that says something about the current medical condition of the patient. The person who undergoes a predictive test is not (yet) a patient. In other words, it concerns a real presymptomatic diagnosis. In general, there is no urgent medical reason to carry out a predictive genetic test. Because such a test may have a dramatic impact, it has 
been stressed that it is of utmost importance for the request for a test to be voluntary and to come from a competent applicant, without any form of external pressure (eg, from a partner or family). ${ }^{21}$ In adults, a multidisciplinary team (with clinical geneticists, psychologists, psychiatrists, neurologists, and social workers) evaluates applications for a predictive genetic test for a condition. During pretest counseling, adequate information is provided about the disorder, the predictive test, and the possible psychological impact of a test on the person. ${ }^{21}$ People who take part in a predictive genetic test should be clearly informed about not only the possibilities but also the limitations and substantial elements of uncertainty that are linked to the test. Such a multidisciplinary approach is necessary to safeguard the well-being of the test applicant and to protect him against the possible pernicious impact of insufficiently prepared tests.

In this light, professional guidelines have always defended the position of voluntary choices and autonomous and informed decision-making in a context of open discussion about familial hereditary diseases. Also, in the case of predictive genetic testing in minors, the option has been made to let the future mature patient decide about such a test instead of letting parents decide without children's consent or assent. In a recent article, Rhodes ${ }^{5}$ challenges this view and questions why this is the case whereas "autonomy is not an issue in medical decisions made on behalf of children whenever doctors and parents impose vaccinations, antibiotic injections or other treatment on children who may scream their opposition." She refers to the fact that genetic diseases are familial diseases and that some family members are already afflicted by the disease. The environment in which the child is growing is "an unavoidable piece of the child's inheritance." As a result, she argues that the decision whether to raise the child with knowledge or ignorance of her or his genetic status is one that the family must make. She argues as well that it does not violate the principle of confidentiality if a minor is being tested on request of the parents. On the basis of parental authority, she argues that parents should be authorized to decide whether to take a sample of their child's blood, have the genetic test performed, and be provided with the genetic information of their children:

Parental authority is the model for making medical decisions on behalf of children. This is a well-accepted social norm that is supported by our laws, and it is usually the most appropriate mechanism for making decisions on behalf of children. Parents are typically deeply concerned with their children's well-being.
However, Rhodes ${ }^{5}$ fails in her position to give a place to minors and to make a distinction between predictive genetic testing of minors and any kind of other medical procedure. We discuss both observations.

First, because young children are not able to make complex decisions for themselves, the authority to make medical decisions on behalf of a child usually falls to the child's parents. Parents (or legal guardians) have indeed received ethical and legal authority over their children's medical care. This includes the right to initiate, refuse, or stop preventive or therapeutic measures. The basis of this position is that parents are in a unique moral relationship with their children and are expected to make decisions that are in the best interests of their children, that is, to act "so as to promote maximally the good of the individual."22 Parents' ethical and legal authority over their child's medical care should be directed toward the promotion of their children's health-related interests. International declarations, ${ }^{23,24}$ various policy documents, and publications $^{25}$ have emphasized that the greater a child's cognitive and social abilities are, the more seriously the preferences of the minor should be taken into consideration. As soon as children are able to communicate and participate in decisions that affect them, they should be encouraged to participate in all aspects of the decision-making process. They should be properly informed about medical issues that affect them, and they should be able to express their views, ask questions, or communicate their worries. Rutter ${ }^{26}$ expressed this as follows:

The implication is that health care professionals should be expected to talk with children, even during the pre-school period, about medical matters that involve them. This needs to be done in ways that the children can understand but that are no different in principle from the exactly comparable need to do so with respect to adults. Thus, most adults can scarcely be expected to understand all the complex considerations that go into decisions about different forms of medical treatment, or different surgical procedures, for specific conditions. It would make no sense to present the patient with the sort of technical evidence that would be taken into account by an expert in the field. It would be generally accepted that it is the duty of health professionals to provide the patient with as much understanding of these issues as possible and to engage them in the decision-making. Exactly the same applies in childhood.

Testing minors at a young age for late-onset genetic diseases denies them the option of deciding about testing later in life, although this would have been possible. 
Second, professional recommendations ${ }^{27}$ implicitly acknowledge that there is a substantial difference between (1) a predictive genetic test for adult-onset diseases and (2) a medical diagnosis that says something about the current medical condition of the patient or a vaccination with the aim of prolonging immunity to specific diseases. The impact of genetic testing differs often from other types of medical interventions. We do not say that genetic testing is unique in one of these respects, but the cumulative complexity of these elements requires that genetic testing should receive careful consideration. First, genetic information is familial. As a result, the test results of a person might have direct implications for relatives, including offspring. Second, presymptomatic and predictive genetic testing provides information about the medical future of a healthy person. The person who undergoes a predictive test is not (yet) a patient. In other words, it concerns a real presymptomatic diagnosis. Third, there is a concern that genetic testing may lead to misuse of the genetic information by third parties, including insurers and employers, to deny, limit, or cancel health insurance or to discriminate against the person in the workplace. Furthermore, genetic information may also lead to stigmatization and discrimination within the community. A genetic test or the result of a genetic test may also lead to psychological distress. Increased anxiety, distress, depression, changed familial relations, changes in self-image, behavioral changes, and an impact on life planning are some of the potential negative psychosocial outcomes that have been reported in the literature as a result of a genetic test. It is clear that these features are not valid for all genetic data and that some of these characteristics are valid also for nongenetic medical data. In this way, genetic information differs not so much principally but rather gradually from other medical data. ${ }^{28}$

Because of the specific character of genetic information and because minors are urged as much as possible to participate in decisions affecting their own health, we support the professional guidelines in their position of delaying such genetic testing. Predictive genetic testing, as well as medical diagnostic evaluations or treatment decisions, should be performed on children if they provide timely medical benefit to the children. If the medical benefits are absent or uncertain, the justification for a specific medical intervention is less compelling. In addition, there should be an effective treatment or intervention for patients identified through early detection, with evidence of early treatment leading to better outcomes than later treatment. For predictive genetic testing for adult-onset diseases, the advantages in terms of medical benefit are absent because of the long period until the onset of the disease and the absence (in the cases studied here) of therapeutic or preventive measures. Because minors do not have any prospect of benefitting from effective treatment now, the question is if nonmedical benefits might provide convincing arguments about whether testing should be undertaken.

\section{NONMEDICAL BENEFITS AND HARM}

Existing professional recommendations have always defended a cautionary position toward predictive genetic testing in minors because of the potential harm that it may lead to. For example, according to the Working Party of the Clinical Genetics Society, ${ }^{10}$

The potential harms caused by childhood genetic testing might include damage to the child's selfesteem, distortion of the family's perceptions of the child, loss of future adult autonomy and confidentiality, discrimination against the child in education, employment or insurance, and adverse effects on the child's capacity to form future relationships.

It is also asserted that the burden of certainty-knowing that one will get a genetic disease later in life-may result in severe psychological harm and even suicide, suicide attempts, and psychiatric hospitalizations ${ }^{29}$; this may be termed the unbearability of certainty. ${ }^{30}$ However, there are difficulties in extrapolating these studies to children. It is simply not known if at-risk individuals would be better or worse if they had the test. There is a lack of informative studies about the psychological impact of predictive genetic testing on minors. Only a few studies have been performed. Grosfeld et al. ${ }^{31}$ studied the psychological reactions of 22 parental couples and 3 single parents of children tested for multiple endocrine neoplasia type 2 . The study showed that parents with favorable test results in their children experienced significantly less anxiety, whereas parents with children having the mutation experienced moderate to high levels of anxiety. Testing for familial adenomatous polyposis (FAP) did not lead to clinically significant changes in psychological symptoms (eg, depression, anxiety behavior, and competence) in tested children or their parents 3 months after testing. ${ }^{32}$ Michie et al. ${ }^{33}$ also did not find significant increases in symptoms of anxiety or depression, but they did find significantly higher anxiety among children who tested positive for FAP versus their tested-negative counterparts. A recent study by Codori et al. ${ }^{34}$ showed that children did not suffer clinically significant psychological distress 
after testing. However, the same study also showed that "it would be clinically irresponsible to ignore the increases in depression and anxiety among children with positive siblings." In general, however, the reactions to the genetic test were rather positive, and negative effects were mostly transitory. Of course, the data are too limited to make conclusive decisions regarding genetic testing in minors, and the favorable reactions may be attributable to the view of multiple endocrine neoplasia type 2 and FAP as treatable diseases.

The introduction of nonmedical benefits and harm in the arguments regarding predictive genetic testing for minors for adult-onset genetic diseases integrates a concept of best interests that involves far more complex matters than physical criteria alone. Rhodes' critique ${ }^{5}$ of best interests, which measure benefit primarily in terms of physical gains, is in the line with the critique issued by the British Medical Association (BMA). The BMA ${ }^{35}$ developed a range of general factors with social and emotional elements that need to be considered when a young patient's best interests are assessed in relation to treatment. Among other things, the BMA emphasizes "the patient's own ascertainable wishes, feelings and values," "the patient's ability to understand what is proposed and weigh up the alternatives," "the patient's potential to participate more in the decision, if provided with additional support or explanations," "the patient's physical and emotional needs," "the risk of harm or suffering for the patient," "the views of parents and family," and "the prioritizing of options that maximize the patient's future opportunities and choices." However, even on the basis of this broad interpretation of the concept of best interests, contrary to the conclusion of Rhodes, the BMA comes to the conclusion that in the case of predictive testing for late-onset disorders, "testing in children should be opposed because it would undermine the future adult's right to make his or her own decision about whether to be tested." Rhodes describes various factors that led her to conclude that "pediatricians and geneticists should encourage reluctant parents to have their children tested-and then accept the parents' decision." ${ }^{5}$ First, Rhodes mentions that

$50-70 \%$ of those tested would also get the good news that they are unaffected. I take those odds alone to be an overwhelming reason for testing children.

She also stresses that almost everyone who is tested can benefit, at least by being relieved of uncertainty. Second, she criticizes the concept of unbearability of certainty because deceiving or withholding information from children can be harmful. Third, she advances that this information can become part of identity: "When this information is disclosed later in life, it can be jarring to identity and very hard to internalize and accept." Fourth, she asserts that delays in learning a child's genetic status prolong the parents' uncertainty and anxiety. In what follows, we dissect these 4 arguments and discuss alternatives.

\section{Good News}

It is clear that for those individuals who do not carry the mutation for a particular disorder, it is possible that many adverse consequences from assumptions of being affected may be averted. There are indeed examples of such good news reported in the literature. ${ }^{36}$ People who undergo genetic testing and receive "good news" may learn definitively, or with a high probability, that they will not develop the disease and transmit it to their children. For those individuals who have the faulty mutation for a particular disorder, it allows anticipation of the future and appropriate planning. The act of testing could also be a catalyst for frank discussion with the family on the genetic aspects of the disorder, which the child is already encountering by living within an affected family. It may prevent children from being deceived or barred from information about genetic diseases.

A major problem related to the argument that genetic testing of minors might bring "good news" is that it does not sufficiently consider the consequences for those who test positive. Not only does it remove the opportunity for the child to make a decision about having the genetic test later in life, but it also often introduces more uncertainty and other risks. It is difficult for the child to live in the knowledge that, while not sick now, he or she has a greater likelihood of becoming sick in the future. Depending on the disease, this predictive value of the results might vary enormously. Although a child with a positive test result for Huntington's disease is almost certain to develop the disorder, many women with a positive test result for breast cancer do not get that disease. Even when a test can detect a mutation capable of causing a disease, the test may not be able to predict with certainty whether disease symptoms will appear, when they will appear, or what the degree of severity will be. In addition, the child is at risk for such harm as stigmatization and discrimination, increased anxiety, distress, depression, changed familial relations, changes in self-image, behavioral changes, and an adverse impact on life planning.

In addition, even favorable news and reassurance may affect people's self-image and the family 
dynamics. It may lead to what is called "survivor guilt" and a sense of stigmatization and exclusion from affected members of the family. ${ }^{37}$ The following quote from Hayes ${ }^{38}$ shows that receiving good news may lead to psychological and social distress and troubling family relations:

It was a long and complex process. Blood samples from numerous members of my family had to be collected and analyzed. I underwent several months of genetic counseling to determine my ability to cope with any possible outcome. After a period of months, nothing remained but the nerve-racking wait for the results.... Finally, the wait was over: my test was negative. The DNA analysis has shown with 96 percent certainty (later increased to 99 percent, with refinement of the testing process) that I had not inherited the gene for Huntington's disease. When I learned the results I cried and laughed. It took months for the news to sink in. I am still adjusting. . . . The incomparable relief I felt at finally being free of the fear and uncertainty was tempered by the painful knowledge that other family members had not been and would not be so lucky.

Moreover, the message of "good news" fluctuates between analytic sensitivity, the ability of a test to detect the various mutations that it was designed to detect, and clinical sensitivity, the ability of the test to detect all patients who will get the disease. Even if the test result is negative, patients might still retain a residual risk of developing the disease. The study of Grosfeld et al. ${ }^{31}$ showed that even parents who received "good news" often were not reassured by the DNA test result, wanted confirmation of the test result, and were willing to continue follow-up of their children who did not have the faulty mutations.

\section{Unbearability of Knowing}

In her analysis, Rhodes 5 is distinguishing 2 separate options:

Either the testing is not performed and the child is raised without the family and the child having information about whether or not the child has inherited the mutation, or the testing is performed and the family raises the child in the context of knowing that the child has or has not inherited the mutation. Logically there are no other options.

However, in this way the author does not take into account the intermediate option of informing children about their genetic risk without performing the predictive genetic test in childhood.

It is clear that it would be wrong to deceive or withhold relevant information from children. Genetic information is relevant and important to children, and concealment of this information denies to children important details about themselves. As Clayton stated, "long experience demonstrates that hiding information from children usually does not work and that efforts to keep secrets leave children feeling deceived and abandoned." 39 Withholding information from the child results in withholding "the power to make informed choices." ${ }^{40}$ Studies show that "those who felt that information had been deliberately withheld from them were deeply resentful and expressed anger and feelings of disempowerment as a result." ${ }^{40}$ Parents are responsible for the health and well-being of their children and have the important responsibility to communicate the genetic risk to their children and to support them in dealing with that risk. We underline the familial character of genetic information and emphasize that genetic risk information should be discussed as openly as possible in a family context. Telling children about genetic risk is generally seen as a parent's responsibility, ${ }^{41}$ but health professionals may be needed in a supporting role.

Of course, open communication about genetic risk between parents and children is not always easy. Feelings of guilt and blame may affect family relationships and hinder communication about genetic risk. ${ }^{42,43}$ Psychological defense mechanisms such as denial and rationalization have been observed as reasons for parents not telling children in Huntington's disease families. ${ }^{44}$ In hereditary breast and ovarian cancer families, studies suggest that some patients use similar strategies to minimize the emotional impact of the risk to themselves and their daughters. As a result, there may be interruptions in the transmission of risk information to some children if a parent declines to tell ${ }^{41}$ or if a sibling or parent dies. ${ }^{45}$ This may be compounded by a tendency for aunts or uncles not to speak with nieces or nephews and/or a sense that they do not have the authority to do so.

Having open communication between parents and a child about genetic risk and the possibility of a genetic test as soon as the minor has the competence to provide consent to it seems to us a better alternative than just testing the minor in childhood. Testing children as an isolated act is not an alternative for open communication: the child might be told once, and it may not be discussed again. It might also confuse or frighten the child. Testing in childhood does not ensure further communication and follow-up. When a minor understands the information given to him and the implications of a positive and negative genetic test for him, his partner, and his possible offspring, he can make a decision (eventually together with his parents) about performing this test. 
A major difference between informing children of the fact that they have been adopted or created with gamete donation and performing a genetic test is that the information is already there in the former case. It is clear that families should not be discouraged from telling their children that they have a genetic risk. Just as in the situation of adoption, informing children about the presence of this risk (or the fact of being adopted) allows children to ask questions and to make statements about undergoing a predictive genetic test themselves (or to learn more about the adoption). Our position is in line with existing guidelines that state that if parents discuss the "child's risk with the child, they will be able to explain to the child that testing will be available at the discretion of the child when the child reaches maturity."13

\section{Identity and Adjustment}

According to Rhodes, ${ }^{5}$

Information becomes part of identity. When a child learns personal genetic information early in life, it can be absorbed and accommodated into identity. When the information is disclosed later in life, it can be jarring to identity and very hard to internalize and accept.

We clearly follow this idea of Rhodes, in the sense that information about genetic risk should not be withheld from children. This of course requires that the children understand "what they are being told, can make sense of the information (according to their age), are not fearful of it and are able to talk about it and ask questions whenever they like." 46 Children should be offered the opportunity to incorporate this information into their self-image, to look to the future, and to plan what to do about their genetic risk. As Skirton notes, "the advantage of telling a child gradually as the opportunity presents itself or as questions arise was stressed by a number of respondents, who felt that there were benefits in being able to absorb the information slowly and so gradually adjust to the altered potential of life." 40 Also, the Genetic Interest Group reports that "children can cope with information about themselves from an early age and that it is much more often the adult who has a problem in giving information." ${ }^{47}$

Disclosure of disease risk may also benefit children when they are told at a young age instead of being told as adolescents or adults. In her study, Skirton reported that "it is easier for a young person to deal with the news of risk than it would be at an older age." ${ }^{40}$ From this perspective, we advance that in building up an identity, it is important that a child be told about the risk for a disease that exists within a family, but it is not necessarily important to tell him whether or not he carries the faulty mutation. We recommend that the child be made aware of genetic conditions in the family that may have an impact on him and that the child be informed about his genetic risk. This enables the child to make a free choice about genetic testing later in life.

\section{Parental Anxiety and Uncertainty}

Rhodes $^{5}$ also advances that delays in learning a child's genetic status prolong parents' uncertainty and anxiety. Various studies ${ }^{48-50}$ have indeed shown that parents believe that detection in childhood might help prepare their children and themselves psychologically for the future. Various parents that have been tested themselves for a specific disease and know that their children are at risk find sometimes the uncertainty of not knowing more burdensome than receiving a negative or positive test result. Therefore, parents often conclude that they should be able to consent to genetic testing in their children for diseases that have their onset only in adulthood.

However, it should be clear that only $10 \%$ to $15 \%$ of at-risk adults opt for Huntington's disease genetic testing. Studies ${ }^{37}$ that have explored the reasons for this low take-up have shown the most important reasons for not being tested were increased risk to children if one was found to be a gene carrier; absence of an effective cure, potential loss of health insurance, financial costs of testing, and the inability to "undo" the knowledge. The risk to relatives, lack of treatment or cure, and fear of losing one's health insurance are important factors in the decision not to be tested.

If parents would test their young children, there would not be able to make this personal evaluation. In this context, it is relevant to refer to the notion of the "right not to know," which is increasingly accepted also at the international level. The right not to know has been recognized, for example, in the European Convention for the Protection of Human Rights and Dignity of the Human Being with Regard to the Application of Biology and Medicine, which states [in article 10(2)] that

Everyone is entitled to know any information collected about his or her health. However, the wishes of individuals not to be so informed shall be observed.

Similarly, the UNESCO Universal Declaration on the Human Genome and Human Rights states (in article 5c) that 
The right of every individual to decide whether or not to be informed of the results of genetic examination and the resulting consequences should be respected.

Testing a minor eliminates the possibility of the minor making use of this "right not to know."

As we have stated previously, it is also clear that testing does not take away all anxieties and uncertainties. Indeed, anxiety and distress might increase when children test positive. We suggest that the most important reasons for letting children decide later about performing such a genetic test probably concern those who will be affected by the disorder. Rhodes ${ }^{5}$ refers in her article to the fact that because parents, "far more than health care providers or policy makers, are the ones who will be living with the repercussions of their choices, the judgment should be theirs." However, we would like to advance the opposite statement, that because minors, far more than their parents, will be living with the repercussions, they should be able to decide about participation in such a genetic test. The presence of severe anxieties and uncertainties in parents about a potential genetic mutation might be an indication for further psychological support in order to address these emotions rather than a clear indication for testing.

\section{CONCLUSIONS}

In her article, ${ }^{5}$ Rhodes challenges the recommendations of the genetic and pediatric communities regarding predictive genetic testing for late-onset genetic disorders for which there are no preventive or therapeutic measures. In this article, we have entered into a dialogue and discussed her various arguments. At the end of this article, we would first like to emphasize that the main reason for the existing guideline not to perform such testing is the fact that testing does not provide "scope for treatment which to any essential degree prevents, defers or alleviates the outbreak of disease or the consequences of the outbreak of disease."15 Second, we question if the parents are entitled to make such decisions. On the one hand, one can intuitively understand that parents feel responsible for the well-being of their children and want to take actions that benefit them and their offspring. On the other hand, we suggest that the responsibility of parents does not go so far that they should be responsible for deciding about performing such a test in childhood. This would be a moral hypertrophy of responsibility. ${ }^{51}$ In this way, responsibility is being stretched endlessly. ${ }^{52}$ We suggest, however, that parents are responsible for the health and well-being of their children and have the important responsibility of communicating the genetic risk to their children and supporting them in dealing with that risk. We underline the familial character of genetic information and emphasize that genetic risk information should be discussed openly in a family context. However, we also emphasize the individual character of this information, the individual decision to undergo a genetic test, and the individual choice to share the result of the genetic test with others. Furthermore, psychosocial concerns incite us to caution. Very few studies have been reported concerning the psychosocial consequences of predictive genetic testing in childhood or adolescence. Even if they did not report long-term negative psychological and social impact, there is no reason to assume that such testing in minors should not be assessed with caution. Studies with adults incite us to do so. Even if there is no clear evidence of harm, there is no clear evidence of benefit. Letting minors decide about predictive genetic testing for late-onset diseases means respecting them as humans with their own individuality and responsibility. Parents and genetic services should be supportive so that minors at risk are informed about their genetic risk and are able to make use of the opportunities of genetic testing later in life.

\section{ACKNOWLEDGEMENT}

The research for this contribution was supported by the Eurogentest Network of Excellence of the European Union (FP6-512148).

\section{DISCLOSURES}

There is nothing to report.

\section{REFERENCES}

1. Harper P, Clarke A. Genetics, society and clinical practice. Oxford, England: Bios; 1997.

2. Biesecker BB. Future directions in genetic counseling: practical and ethical considerations. Kennedy Inst Ethics J 1998; 8: 145-160.

3. Mahowald MB, Verp MS, Anderson RR. Genetic counseling: clinical and ethical challenges. Annu Rev Genet 1998; 32: 547-559.

4. Allan D. Ethical boundaries in genetic testing. CMAJ 1996; 154: 241-244.

5. Rhodes R. Why test children for adult-onset genetic diseases? Mt Sinai J Med 2006; 73: 609-616.

6. The American Society of Human Genetics Board of Directors and the American College of Medical Genetics Board of Directors. Points to consider: ethical, 
legal, and psychological implications of genetic testing in children and adolescents. Am J Hum Genet 1995; 57 : 1233-1241.

7. Human Genetics Society of Australasia. Child testing policy (2005). Available at: http://www.hgsa.com.au. Accessed March 2008.

8. German Society of Human Genetics. Statement on genetic diagnosis in children and adolescents (1995). Available at: http://www.gfhev.de/en/gfh. Accessed March 2008.

9. Committee on Bioethics. Ethical issues with genetic testing in pediatrics. Pediatrics 2001; 107: 1451.

10. Clarke A. The genetic testing of children. Working Party of the Clinical Genetics Society (UK). I Med Genet 1994; 31: 785-797.

11. Canadian College of Medical Geneticists. Genetic testing of children (2000). Available at: http://ccmg. medical.org. Accessed March 2008.

12. Bioethics Committee Canadian Paediatric Society. Guidelines for genetic testing of healthy children. Paediatr Child Health 2003; 8: 42-45.

13. American Medical Association. Testing children for genetic status (1995). Available at: http://www.amaassn.org. Accessed March 2008.

14. Committee for Public Relations and Ethical Issues of the German Society of Human Genetics. Statement on genetic diagnosis in children and adolescents (1995). Available at: http://www.gfhev.de/en/gfh. Accessed March 2008.

15. Danish Council of Ethics. Genetic investigation of healthy subjects-report on presymptomatic gene diagnosis (2001). Available at: http://www.etiskraad.dk/sw293.asp. Accessed March 2008.

16. Human Genetics Society of Australia. DNA presymptomatic and predictive testing for genetic disorders (2002). Available at: http://www.hgsa.com.au/policy/ dnaptgd.html. Accessed March 2008.

17. Belgian Society of Human Genetics. Guidelines for predictive genetic testing for late onset disorders (2003). Available at: http://www.beshg.be. Accessed March 2008.

18. European Society of Human Genetics. Provision of genetic services in Europe-current practices and issues (2001). Available at: http://www.eshg.org. Accessed March 2008.

19. Stultiens L, Goffin T, Borry P, et al. Minors and informed consent: a comparative approach. Eur $J$ Health Law 2007; 14: 21-46.

20. Health Act-Law No. 546 of 24 June 2005.

21. Evers-Kiebooms G, Welkenhuysen M, Claes E, et al. The psychological complexity of predictive testing for late onset neurogenetic diseases and hereditary cancers: implications for multidisciplinary counselling and for genetic education. Soc Sci Med 2000; 51: 831-841.

22. Buchanan AE, Brock DW. Deciding for Others. Cambridge, England: Cambridge University Press; 1989.

23. Charter of Fundamental Rights of the European Union (2000). Available at: http://www.europarl.europa.eu/ charter/default_en.htm. Accessed March 2008.

24. UNESCO. Universal Declaration on the Human Genome and Human Rights (1997). Available at: http://portal.unesco.org. Accessed March 2008.
25. Alderson P, Montgomery J. Health Care Choices: Making Decisions with Children. London, England: Institute for Public Policy Research; 1996.

26. Royal College of Psychiatrists Report. Appendix 2-Children's level of understanding of medical decisions. Guidance for researchers and for ethics committees on psychiatric research involving human participants (2001). Available at: http://www.rcpsych.ac.uk. Accessed March 2008.

27. Borry P, Stultiens L, Nys H, et al. Presymptomatic and predictive genetic testing in minors: a systematic review of guidelines and position papers. Clin Genet 2006; 70: 374-381.

28. Dierickx K. Genetic privacy and the family. Ind J Fam Stud 2004; 2: 68-80.

29. Bird TD. Outrageous fortune: the risk of suicide in genetic testing for Huntington disease. Am J Hum Genet 1999; 64: 1289-1292.

30. Almqvist EW, Bloch M, Brinkman R, et al. A worldwide assessment of the frequency of suicide, suicide attempts, or psychiatric hospitalization after predictive testing for Huntington disease. Am J Hum Genet 1999; 64: 1293-1304.

31. Grosfeld FJ, Beemer FA, Lips CJ, et al. Parents responses to disclosure of genetic test results of their children. Am J Med Genet 2000; 94: 316-323.

32. Codori AM, Petersen GM, Boyd PA, et al. Genetic testing for cancer in children. Short-term psychological effect. Arch Pediatr Adolesc Med 1996; 150: 1131-1138.

33. Michie S, Bobrow M, Marteau TM. Predictive genetic testing in children and adults: a study of emotional impact. J Med Genet 2001; 38: 519.

34. Codori AM, Zawacki KL, Petersen GM, et al. Genetic testing for hereditary colorectal cancer in children: long-term psychological effects. Am J Med Genet 2003; 116A: 117-128.

35. British Medical Association. Human genetics: choice and responsibility. Oxford, England: Oxford University Press; 1998.

36. Fanos JH. Developmental tasks of childhood and adolescence: implications for genetic testing. Am J Med Genet 1997; 71: 22-28.

37. Quaid KA, Morris M. Reluctance to undergo predictive testing: the case of Huntington disease. Am JMed Genet 1993; 45: 41-45.

38. Hayes CV. Genetic testing for Huntington's disease-a family issue. N Engl J Med 1992; 327: 1449-1451.

39. Clayton EW. Genetic testing in children. J Med Philos 1997; 22: 233-251.

40. Skirton H. Telling the children. In: Clarke A, editor. The Genetic Testing of Children. Oxford, England: Bios; 1998; 103-111.

41. Forrest K, Simpson SA, Wilson BJ, et al. To tell or not to tell: barriers and facilitators in family communication about genetic risk. Clin Genet 2003; 64: 317-326.

42. Speice J, McDaniel SH, Rowley PT, Loader S. Family issues in a psychoeducation group for women with a BRCA mutation. Clin Genet 2002; 62: 121-127.

43. Fanos JH, Johnson JP. Barriers to carrier testing for adult cystic fibrosis sibs: the importance of not knowing. Am J Med Genet 1995; 59: 85-91.

44. Martindale B. Huntington's chorea: some psychodynamics seen in those at risk and in the responses of the helping professions. Br J Psychiatry 1987; 150: 319-323. 
45. Peterson SK, Watts BG, Koehly LM, et al. How families communicate about HNPCC genetic testing: findings from a qualitative study. Am J Med Genet 2003; 119C: 78-86.

46. Malpas PJ. Why tell asymptomatic children of the risk of an adult-onset disease in the family but not test them for it? J Med Ethics 2006; 32: 639-642.

47. Dalby S. GIG response to the UK Clinical Genetics Society report "The genetic testing of children". J Med Genet 1995; 32: 490-491.

48. Campbell E, Ross LF. Parental attitudes and beliefs regarding the genetic testing of children. Community Genet 2005; 8: 94-102.

49. Hamann HA, Croyle RT, Venne VL, et al. Attitudes toward the genetic testing of children among adults in a Utah-based kindred tested for a BRCA1 mutation. Am J Med Genet 2000; 92: 25-32.

50. Benkendorf JL, Reutenauer JE, Hughes CA, et al. Patients' attitudes about autonomy and confidentiality in genetic testing for breast-ovarian cancer susceptibility. Am J Med Genet 1997; 73: 296-303.

51. ten Have HA. Responsibilities and rationalities: should the patient be blamed? Paper one: The distinction between prospective and retrospective responsibility. Health Care Anal 1994; 2: 119-123.

52. Dierickx K. Autonomous decisions in assisted procreation and genetic diagnosis. In: Haker $\mathrm{H}$, Beyleveld D, editors. The Ethics of Genetics in Human Procreation. Aldershot, England: Ashgate; 2000; $131-138$. 